\title{
Filantropía y anarquismo: imaginario prometeico y espacios de representación de Valparaíso en Edwards Bello, Swinglehurst, Darío, V. D. Silva y González Vera
}

\author{
Adolfo de Nordenflycht B. \\ Pontificia Universidad Católica de Valparaíso \\ adolfodenordenflycht@gmail.com
}

RESUMEN: Este artículo se propone dar cuenta de las diferentes modalidades en que la representación literaria pone en tensión el imaginario prometeico del Valparaíso de fines del siglo xix y principios del siglo $\mathrm{xx}$, otorgando relevancia a algunos de los mitemas que lo conforman como filantropía o anarquismo, para lo cual se examinan textos de escritores implicados en las migraciones extranjera e interna (Edwards Bello, Swinglehurst, Darío, V. D. Silva y González Vera), que entran en diálogo con los espacios urbanos y el imaginario social de un Valparaíso signado por el progresismo y la modernización.

Palabras Clave: imaginario prometeico, Valparaíso, literatura local, modernidad. 


\section{Philanthropy and anarchism: Promethean imaginary and spaces of representation of Valparaíso in Edwards Bello, Swinglehurst, Darío, V. D. Silva and GonzÁlez Vera}

ABSTRACT: This article intends to give an account of the different modalities in which literary representation puts into tension the Promethean imaginary of Valparaíso in the late nineteenth and early twentieth century, giving prominence to some of the mythemes that go on to define it as philanthropy or anarchism. For this purpose, several texts of writers involved in the foreign and internal migrations are examined (Edwards Bello, Swinglehurst, Darío, V. D. Silva, González Vera), texts that dialogue with the urban spaces and the social imaginary of a Valparaíso marked by progressivism and modernisation.

KEYwords: Promethean imaginary, Valparaíso, local literature, modernity.

\section{INTRODUCCIÓN}

El prometeísmo desprendido de la Kulturphilosopbie y que instituye el imaginario social asociado a los desarrollos del capitalismo y del positivismo suscitó, con la explosión (Reinhardt, citado en García Gual) de toda su riqueza simbólica durante la modernidad, la evolución y derivación de mitemas que se le asocian, como la cultura, la técnica, la filantropía, el martirio, el sacrilegio (engaño, robo), etcétera, que recibieron nuevas y contrapuestas expresiones en las manifestaciones literarias, compendiando una actitud que desafía y combate las opresiones políticas y religiosas. Ya en la modernidad romántica, la imagen prometeica funciona como un símbolo que no se articula en la sucesión del mito, pero sí en nuevos y diversos conjuntos (como el Fausto goetheano o el Prometeo de Shelley y el Frankenstein de Mary Shelley), que dramatizan una figura que se ha fosilizado, un mitologema constituido por diversos mitemas ${ }^{1}$ que, como señala Durand, se desarrollan fragmentándose, derivando, deteriorándose, pero conservando cierta perennidad, a través de un proceso cuya evolución no es ajena a las alteraciones tanto de la literatura como de la historia.

\footnotetext{
Nos interesa destacar que los mitemas son entendidos como unidades de base, o mínimo común denominador de sentido simbólico, que están relacionados en un sistema mítico más amplio, pero que a la vez funcionan autónomamente.
} 
En el espacio literario latinoamericano, dicho imaginario prometeico se aprecia particularmente en algunos aspectos del modernismo, donde los mitemas prometeicos se conciben y surgen de esa nueva coyuntura social que, según Rama (Rubén Darío), termina con el poeta de profunda influencia y participación en el escenario político del país y lo sitúa frente a una sociedad que se distanciaba de la generación de nuevas demandas de producción artística.

Me propongo observar de qué modo se manifiesta y se pone en tensión el imaginario prometeico en el espacio local de Valparaíso, considerando textos que refieren a centros o ejes geoculturales ${ }^{2}$ que influyeron en la articulación de los espacios de representación ${ }^{3}$ del Valparaíso de la época. Se trata de textos de escritores implicados en las migraciones extranjera e interna, que entran en diálogo con los espacios urbanos y el imaginario social de un Valparaíso signado por el progresismo y la modernización: Valparaíso Songs (1913) del poeta inglés y empresario del acero radicado en el Puerto, Henry Edward Swinglehurst; "Album porteño", incluido en Azul (1888) del nicaragüense Rubén Darío; "Trágame” en Hacia allá (1905) de Victor Domingo Silva, migrante del interior que vivió quince años en Valparaíso; "Una mujer", relato incluido en Vidas minimas (1921) de José Santos González Vera; Valparaíso, ciudad del viento (1931) de Joaquín Edwards Bello, descendiente de los precursores migrantes extranjeros, que más tarde, rememora fantasmáticamente el Valparaíso de principios de siglo $\mathrm{xx}$.

Los sujetos representados en los textos de estos autores entablan con Valparaíso relaciones de otredad bastante singulares, a partir del hecho de

2 Como se sabe, la expresión pertenece a Rodolfo Kusch, para quien "detrás de toda cultura está siempre el suelo" (109). La distinción de centros o ejes geoculturales que "repercuten en todo sentido a través de toda la historia..." explican el enraizamiento de una determinada cultura a un territorio. (Para el caso de la conformación de la geocultura argentina -que es la analizada por Kusch- los ejes examinados explicarían su mediterraneidad).

3 Los espacios de representación no necesitan obedecer a reglas de consistencia o cohesión. Llenos de elementos imaginarios y simbólicos, tienen su origen en la historia -en la historia del pueblo y en la historia de cada individuo que pertenece a este pueblo- (Lefebvre 41). 
establecer con la ciudad-puerto "zonas de contacto" (Pratt) $)^{4}$ diferidas y diferenciales ${ }^{5}$ (Chaitin), de cuya conjunción e interrelación, en otras palabras, de cuya emergencia (Foucault, Nietzsche) se puede reconocer una identidad "geocultural" de Valparaíso, distinta de la impuesta a escala nacional desde las decisiones de la metrópolis. De esta forma, el "conocimiento local"" de Valparaíso se intersecta y conflictúa con un conocimiento otro, a partir de una relación primeramente de espacialidad. Este "conocimiento otro" se asienta en las distintas images ${ }^{7}$ de Valparaíso que los escritores señalados sustentan, develando en un plano macrodiscursivo el valor ideológico y político de los textos literarios, al condensar y elaborar significaciones imaginarias del medio social y cultural en el que se producen y recepcionan.

\section{2. "La Musa de Valparaíso es la Bolsa"}

Una vez completada la independencia del país hacia 1818, y en el marco de las ideas de progreso, Valparaíso dejará atrás la impronta colonial de ser un núcleo urbano sin acta de fundación, un fondeadero logístico para el controlado comercio ultramarino, "un poblacho mal construido

4 Pratt usa esta expresión para referirse “al espacio en que pueblos geográfica e históricamente separados entran en contacto y establecen relaciones duraderas, relaciones que usualmente implican condiciones de coerción, radical desigualdad e insuperable conflicto (...) 'zona de contacto' es un intento de invocar la presencia conjunta, espacial y temporal, de sujetos -anteriormente separados por divisiones geográficas e históricas- cuyas trayectorias se intersectan" (Pratt 26). El uso de este concepto para fines de este trabajo radica en la relación conflictiva que se establece entre dos culturas en un espacio-tiempo particular y no en su sentido de encuentro colonial en que lo piensa la autora.

$5 \quad$ Chaitin advierte que "ni la totalidad ni lo individual existen en sí mismos y por sí mismos; sino que lo individual es producto de las diferencias con los otros; y, por tanto, la totalidad no puede existir de forma independiente, ya que entonces no habría nada de lo que diferir, excepto de la no-existencia, de la nada" (Chaitin 156).

“(...) local no únicamente por lo que hace al lugar, tiempo, clase y variedad de resultados, sino en referencia a sus acentos - caracterizaciones vernáculas de lo que sucede conectadas a imaginarios vernáculos de lo que puede suceder-" (Geertz 241).

En el ámbito del comparatismo, Moll sostiene que "toda image se constituye a través de una comparación continua que va de la identidad a la alteridad, porque siempre hablar de los otros es también una forma de revelar algo de sí" (Moll 349). 
y secundario, un aldeón adonde recurrían los santiaguinos por pura necesidad", como lo describía en 1910 Víctor Domingo Silva (Monografía bistórica 28), y recibirá, primero con cierta vacilación desde la década de 1830, pero desde medio siglo en adelante con enérgica resolución, la fuerte inmigración extranjera e interna, que contribuyó a desarrollar una economía asentada en la revolución industrial. Esto le fue otorgando la fisonomía de una ciudad cosmopolita y pujante, transformándola en pocas décadas en un emporio comercial, centro de actividades navieras y mercantiles, principal foco económico y la ciudad más moderna de la nación, lo que se manifestó en una serie de iniciativas y de obras debidas al empuje del capitalismo mercantil-liberal y los avances de la técnica. De este modo, el que fuera un puerto marginal en la red de puertos del Pacífico, en un lapso de poco más de cincuenta años -desde mediados de la década de 1850 a fines de la década de 1910 - triplica su población y eleva de manera exponencial su recaudación por derechos de aduana ${ }^{8}$. En todo caso, su impulso como ciudad se debió, sobre todo, a la incorporación de importantes grupos de migrantes internos y extranjeros seducidos por lo que Estrada describe como "la notoria vitalidad de la ciudad, de la cual ellos mismos eran la principal fuente de origen (...) conformando así una sociedad que desarrollará una identidad dinámica y peculiar totalmente distinta de la del pais"' (13, destacado es nuestro).

En efecto, el arribo de comerciantes ingleses, norteamericanos, franceses, incrementó la febril actividad comercial y bursátil, asentada en la incorporación de las tecnologías modernas, que caracterizó al Valparaíso

8 Como bien señala Rama, "la incorporación de América Latina a la economíamundo, se intensificó a partir de 1870 y aunque dejó marca profunda en todos los países, privilegió a las antiguas zonas marginales del Imperio Español" (Máscaras democráticas 109). Por su parte, Leopoldo Sáez (64-65) señala que el crecimiento de Valparaíso hasta el siglo XVIII fue muy lento, y cita a Vicuña Mackenna quien dice que "Valparaíso no era, a la verdad, sino un pueblo de frailes y cañones". En todo caso, consigna Sáez que en el último tercio del siglo XVIII "[l]a población porteña puede estimarse en tres mil habitantes". El censo realizado en 1796 "registró 2973 habitantes, un aumento notable, ya que la población en 1775 no pasaba de 2000 personas".

La expresión completa de Estrada, señala que "la notoria vitalidad de la ciudad, de la cual ellos mismos eran la principal fuente de origen: aventureros, buscadores de riqueza, jóvenes dispuestos a enfrentar desafíos y a lograr una posición que difícilmente podrían alcanzar en los pueblos del interior, conformando así una sociedad que desarrollará una identidad dinámica y peculiar totalmente distinta de la del país" (13). 
decimonónico, pero a su vez incorporó conflictos y dinámicas sociales provenientes de las ideas positivistas y liberales que "enfatizaron el rol del individuo y las formas de sociabilidad como un modelo representativo de lo moderno" (Rubio 21) que vinieron a cambiar el austero ideario de progreso y sacrificio de la antigua aristocracia ilustrada nacional, reemplazándolo por el cosmopolitismo, la frivolidad, la ostentación y el lujo de una pujante oligarquía porteña. Ello trajo aparejado una transformación en las prácticas espaciales urbanas y los espacios de representación mediante los cuales el individuo liberal, enriquecido rápidamente, promueve un imaginario cosmopolita y comercial que determina emplazamientos y espacios representados, públicos y privados, de una burguesía que fundó su reconocimiento social en la riqueza lograda y en el refinamiento de sus costumbres, resultantes de los avances tecnológicos incorporados a la producción.

Esta circunstancia supuso que el prometeísmo, al menos para el caso del imaginario local de Valparaíso, se desplegó en un flujo delimitado por un extremo "positivo", que tomó figura en la filantropía impulsada por la ideología dominante y otro "negativo", de los marginados y disidentes, que se manifiesta principalmente en la solidaridad y en la actividad de raíz anarquista. Estos extremos revelan la prevalencia de distintos mitemas de la poderosa figura moderna de Prometeo, por una parte, el filántropo como donador generoso del fuego (la técnica y el progreso) a los hombres, bienhechor y altruista, que sin embargo, escamotea y oculta formas de poder hegemónico, control social y de dominación caracterizadores del desarrollo del capitalismo oligárquico decimonónico, heredero del colonialismo en nuestro continente, cuestión que a su vez explica el surgimiento de una suerte de filantropía negativa representada por el anarquismo que asume el mitema de "arrebatador del fuego".

De hecho, la oligarquía porteña, conformada en parte importante por extranjeros y sus descendientes, no podía justificarse ante sí misma con una aristocrática "pureza de sangre", pero sí por su afán progresista cuya "distinción individual con proyección social, se fundaba en la consolidación pública de una conducta ajustada a la dignidad y la honradez" (Rubio 28). Esto explica el incremento de la filantropía en el Valparaíso de la época, que vino a ejercer como una forma de validación social, sin que ello impidiera, por otra parte, que se practicara una forma de vida dispendiosa y derrochadora, experimentada casi como consecuencia natural de la fe en 
el progreso comercial e industrial ${ }^{10}$, como la representa Edwards Bello en su novela de 1931 ambientada a principios del siglo xx, novela varias veces revisada y retitulada, para terminar por llamarse simplemente Valparaíso. Escribe Edwards Bello:

A mediados de año la temperatura de los negocios bajó. Era cosa corriente en la ciudad convulsionada por la bolsa. "La musa de Valparaíso es la Bolsa” había dicho Stepton. El mineral andino salía por la calle Prat; lo cotizaban en la calle Prat, entre las tortillas de erizos del Restaurante del Cambio y las sopas de tortuga de Bunout. El nerviosismo del Puerto anunciaba un trastorno apocalíptico; la gente bebía, jugaba, remolía. El perfume violento de la riqueza mareaba a la gente metódica; la hacía salir de sus negocios donde habían juntado plata y la perdían en pocos días (267).

En efecto, la Bolsa de Valparaíso, la primera que inicia actividades en el país, potenciará no solo la riqueza local sino que, de la mano con la industria, incrementará la fe ciega en el progreso que trae la técnica y el capitalismo posterior a la revolución industrial, como lo sostiene en sus Valparaíso Songs de 1913 Henry Edward Swinglehurst, que arribó a Valparaíso en 1880 como comerciante, llegando a ser un acaudalado filántropo y mecenas de pintores y poetas. Expresa en "Spes et lux nostra", título suficientemente decidor de uno de sus poemas (Swinglehurst 130): "Soy un Matterist. La materia es la electricidad. La electricidad es la Materia. Dios es la Electricidad"11. El sujeto de sus poemas, condensado en la denominación de "El poeta imperial" (¿el propio Swinglehurst? ${ }^{22}$ ), representa esa figura foránea que arrastra hasta esta parte del mundo la lógica capitalista. En

10 Eduardo de la Barra ya exponía su fe en el progreso que traían las fábricas en la balada de 1875 "Canto a la fraternidad en la industria", en la que hace decir a ésta: "Yo todos los pueblos / Reúno en un haz, / Empujo el progreso / El yunque es mi trono, / La fragua mi altar, / Mi ley el trabajo, / Y afianzo en el mundo la unión y la paz. / Mi imperio la tierra, y el aire y el mar. / La inerte materia / Yo sé transformar, / Y aduno en mis moldes / La luz de la ciencia, del arte el ideal".

11 "I am a Matterist. Matter is electricity. Electricity is Matter. God is Electricity". 12 Además del poema que tiene este título, el ejemplar que revisamos (con correcciones y anotaciones de puño y letra del autor) incluye un volante adosado que se encabeza con la pregunta "Who is the imperial poet?", que da a entender que, al menos, se trataría de una idealización del propio Swinglehurst. 
un texto titulado "Jottings" expresa a manera de aforismos ideas como: "No es el dinero que usted tiene, lo que le hace rico, sino el empleo que usted le da", y también: "Un caballero lleva sus calidades a su negocio, y lo dignifica" (Swinglehurst 160) ${ }^{13}$. Su convicción recae en las potencialidades del individualismo, "El socialismo es una fuerza: el Estado sin embargo no puede hacer todo, y la mayor altura del Estado siempre será esa donde la individualidad tiene el juego más libre" (Swinglehurst 161) ${ }^{14}$ y deposita sus convicciones en el capitalismo, confíando que "el mundo pagará bien a un buen capitalista", guardando en consideración que "no todo capitalista es ladrón, así como no todo hombre de trabajo es honesto". Se desprende también de los textos de Swinglehurst que la cultura debe ser una especie de filtro o prisma técnico por el que atraviesa la naturaleza, que de esta forma se ve conquistada por el arte. Así lo expresa en una breve prose titulada Culture:

El arte es lo mejor de la Naturaleza, modificada por lo mejor del Arte. (...) la Cultura no es el privilegio del rico, sino más bien de todo el que trabaja: de los que la buscan temprano por la mañana, antes que comiencen a ganarse el pan, y en el reposo de la tarde, cuando su jornada ha terminado. (...) la Cultura es alegría: es paz, pero sobre todo, esto es la forma más alta de conquista, la conquista de Mí mismo (Swinglehurst 61) ${ }^{15}$.

Como se aprecia, la idea de cultura de Swinglehurst es la posibilidad filantrópica de armonía, concepción nacida de la segunda Revolución industrial, y que se corresponde con la idea burguesa de la cultura y el arte, en un intento por orientarlos hacia la sociedad de consumo. "La burguesía [sostiene Kusch (69)] crea museos, salas de concierto, o habla de eternidad o de universalidad sencillamente para ratificar que arte es materia de

13 "It is not the money that you have, that makes you wealthy, but the use you put it to". "A gentleman carries his qualities into his business, and dignifies it".

14 "Socialism is a force: the State however cannot do everything, and the greatest State will always be the one where individuality has the free-est play".

15 "Art is the best in Nature, modified by the best in Art. (...) Culture is not privilege of the rich, but rather of all who work: of those who seek it in the early morning, before their bread-winning begins, and in the repose of the evening, when their toils are over. (...) Culture is joy: it is peace, but above all, it is the highest form of conquest, the conquest of Self". 
consumo y no de creación". Pero precisamente de esta posición burguesa armonizadora y universalista sobre la cultura y el arte nace la crisis cultural ${ }^{16}$, debido a que la cultura, sobre todo en el continente americano, que arrastra consigo un proceso colonial, no puede entenderse como una armonía de elementos, ni menos como una sumatoria o acumulación de obras dispuestas para el consumo, sino en su función en tanto estrategia resolutiva de un problema vital de la comunidad física y simbólica que entendemos por lo local. Sin embargo, no puede obliterarse del todo la posición sostenida por Swinglehurst y otros mecenas y filántropos porteños decimonónicos. La instalación burguesa de salas, museos, certámenes y círculos literarios cumplió la función de legitimar, en tanto prácticas y discursos, el movimiento artístico en general, que comenzaba a situarse en la nueva coyuntura social que empujaba a los artistas hacia la profesionalización. De hecho, es el prometeísmo filantrópico instituido el que permite sostener la estadía de Rubén Darío en Valparaíso y la publicación de $A$ zul en 1888. Más aún, aportará el sustrato institucional de una cultura armónica en la conflictiva renovación de las artes y las letras en el espacio americano, que traerá el modernismo dariano desplegando otros mitemas del imaginario prometeico.

\section{Del "POETA IMPERIAL" AL "LÍRICO INCORREgIBLE"}

En “Álbum porteño", relato contenido en Azul (1888), se construye la siguiente image del Valparaíso de la década de 1880:

Sin pinceles, sin paleta, sin papel, sin lápiz, Ricardo, poeta lírico incorregible, huyendo de las agitaciones y turbulencias, de las máquinas y de los fardos, del ruido monótono de los tranvías y el chocar de las herraduras de los caballos con su repiqueteo de caracoles sobre las piedras; de las carreras de los corredores frente a la Bolsa; del tropel de los comerciantes; del grito de los vendedores de diarios; del incesante bullicio e inacabable hervor de este puerto; en busca de impresiones y de cuadros, subió al cerro Alegre que, gallardo como una roca florecida, luce sus flancos verdes, sus

16 "No hay paz en la cultura, como no hay belleza, ni tampoco universalidad" (Kusch 69). 
montículos coronados de casas risueñas escalonadas en la altura, rodeadas de jardines, con ondeantes cortinas de enredaderas, jaulas de pájaros, jarras de flores, rejas vistosas y niños rubios de caras angélicas. Abajo estaban las techumbres del Valparaíso que hace transacciones, que anda a pie como una ráfaga, que puebla los almacenes e invade los bancos, que viste por la mañana terno crema o plomizo, a cuadros, con sombrero de paño, y por la noche bulle en la calle del Cabo con lustroso sombrero de copa, abrigo al brazo y guantes amarillos, viendo a la luz que brota de las vidrieras, los lindos rostros de las mujeres que pasan (Darío 82-83).

Sin abandonar las imágenes del progresismo y el cosmopolitismo, el poeta nicaragüense instala el conflicto mediante perspectivas críticas que revelan un "cosmopolitismo discrepante" (Clifford), que según Mellino "viene a significar una especie de localismo progresista, de resistencia de lo local ante lo global. En pocas palabras, el 'cosmopolitismo discrepante' no se presenta como una superación de las identidades culturales a favor de un universalismo igualitario y abstracto" (179).

La discrepancia dariana del universalismo burgués igualitario y abstracto se aprecia primero en la división entre lo que significan para la modernidad local el plan y los cerros. El primero, receptáculo directo del progreso y la técnica, los segundos como el espacio donde refugiarse del ruido y el vértigo articulando una geografía simbólica que propone un Valparaíso en que se tensiona la ciudad moderna. Un segundo aspecto se aprecia al interior de uno de los espacios, el plan, donde coexisten las contradicciones resultantes de las implantaciones ortopédicas de lo moderno en la periferia: así en el texto dariano, las agitaciones y turbulencias corresponden tanto a los modernos tranvías como al chocar de las herraduras de los caballos.

Ahora bien, quien coloca en tensión estos espacios es el "lírico incorregible", que se desplaza develando las multiplicidades que habitan y conforman las resistencias locales de la ciudad-puerto ante la incipiente globalidad, resistencias de la "pequeña ciudad" (Kusch) que reside en, y a la vez, se confronta con la ciudad latinoamericana forzadamente cosmopolita. La modernidad agudiza y propone un nuevo escenario social a la escisión de la ciudad, pero a la vez sus habitantes y las prácticas de estos fragmentan esta misma escisión. Por ello el relato dariano se presenta como "Álbum"; un conjunto de fragmentos cuasi fotográficos, a través de los que se presenta la emergencia de nuevas tensiones entre descendientes de 
emigrantes (empresarios, capitalistas, comerciantes, liberales) y población flotante del interior del país.

\section{4. "En LA OlLA REvUelta dE RAZAS"}

La confrontación entre los cerros y el plan se amplía y acentúa en la representación de los espacios locales que hace Edwards Bello, al tiempo que la mirada del narrador protagonista incorpora una otredad que es el mar. El niño que fuera el sujeto burgués que narra sus memorias en Valparaíso ciudad del viento se siente maravillado por "esas calles del puerto donde se leen enseñas cosmopolitas" (37). Sin embargo, para Edwards Bello, Valparaíso se termina asimilando a la pequeña ciudad provinciana ("el viejo Almendral") que permanece alojada al interior del puerto cosmopolita:

En Valparaíso, cuando comenzaba este siglo, no había secretos. Todo se sabía. Si nos comprábamos zapatos, si nos cortábamos el pelo, se notaba enseguida. Se sabía cuando había enfermos y se contaban detalles truculentos de las operaciones. Después, la muerte, deseada casi siempre era lamentada en coro (Edwards Bello 126).

Una práctica que termina por influenciar a sus habitantes, excepto a los ingleses:

No obstante el progreso y el cosmopolitismo, Valparaíso padecía de las manías de los pueblos chicos. Solamente los gringos demostraban un tacto especial para vivir olímpicamente, ajenos a las pequeñas intrigas. Yo no podía librarme de las manías microscópicas y de orden visual (Edwards Bello 268).

Esta fisura se irá ampliando y acentuando en la dicotomía entre plan y cerro. Así lo denota el niño que sube por primera vez al cerro a matricularse en un "colegio famoso en el Pacífico", un núcleo fronterizo en que coexisten los hijos de emigrantes ingleses y los hijos de "buenas familias peruanas, argentinas y bolivianas, [que] trajeron a sus hijos para que se nutrieran en las aulas de Mac-Kay and Sutherland" (Edwards Bello 36). 
Mi padre reflexiona y suspira mientras sube el cerro. Se ve el mar chiquito desde arriba; es un pozo. No sé porqué el paisaje es triste, violento, amargo.

(...) Bajamos el cerro. El abismo. La mirada se derrumbaba en el mar infinito, sin dársenas, ni islas, ni golfos, como vi en las fotografías que tiene mi padre de Nápoles y Ámsterdam. Impresión de cráter, de cosmos. La retina es incapaz de sujetarse en los árboles y las casas; rueda al mar, al fondo del mar. Es un paisaje para gente fría, sin imaginación.

(...) Misterio del plan y del cerro; dos mundos que ni se quieren ni se conocen. Uno es intruso arriba y ellos son intrusos abajo. (Edwards Bello 35, 36 y 37).

Si la subjetividad se construye entre la praxis social -el aquí/ahora- y el ejercicio de la memoria -entonces/allá- que, siguiendo a Lefebvre ${ }^{17}$, generan con su articulación las tres experiencias del espacio interconectadas, la construcción representacional de Valparaíso del niño burgués que sube por vez primera el cerro no termina por desplazarse por completo desde las "representaciones del espacio" (las imágenes de Ámsterdam y Nápoles que median su visión) al "espacio representacional". En otras palabras, el conocimiento local se encuentra eclipsado por ese conocimiento otro nacido de la práctica y la memoria mediada de los hijos de emigrantes europeos. Para el narrador de Edwards, con el correr del tiempo, Valparaíso progresivamente se vuelve distinto, configurado en suertes de fragmentos caleidoscópicos de variopintos elementos europeos que se mezclan, se confunden, se trastruecan, se amalgaman construyendo un nuevo paisaje interpretado y un nuevo tipo de hombre:

El Puerto, con sus negocios quiméricos, (...) Tiendas, hoteles, caballerizas, studs, modistas de París, afloraban como callampas bajo la lluvia de oro.

17 A saber: "práctica espacial", es decir, la percepción y sensibilidad de la experiencia espacial, atribuida a un criterio de productividad instaurado por la modernidad; "representaciones del espacio", el espacio conceptuado por esa práctica espacial (como las primeras representaciones sobre América desde Europa), el espacio de científicos, planificadores, urbanistas; y por último, el "espacio representacional", el espacio representado por los usuarios de cada cultura particular, por medio de imágenes y símbolos (ver Lefebvre). 
(...) La población enriquecida prefería el plan, el Cerro Alegre y Viña del Mar, lo más lejos posible del chango nativo, de la moral ñoña y de la hipocresía levítica. (...) En la calle Esmeralda triunfaban los rostros flamantes de los importadores de novedades. Habían surgido tiendas inglesas, chilenas, italianas, españolas. La ciudad tomaba un carácter propio. (...) En la olla revuelta de razas se formaba un tipo de hombre inconfundible, de flor en el ojal y chaleco de piqué: el porteño. Hombre nuevo aficionado al Sandow y los bailes novísimos: Boston, Pas de Patineurs, Washington Post y Valse Renversante (Edwards Bello 269-270).

No obstante, en los resquicios coloniales que aún guardaba la ciudad el asunto era distinto, incluso parece tratarse de otra ciudad, esa pequeña ciudad inserta en la cosmopolita y que al sujeto comienza a parecerle cada vez más lúgubre y sombría, y de allí el particular extrañamiento de los hijos de los emigrantes que articulan un espacio fronterizo de nuevas intersecciones:

Me sentí contento de estar en la calle Prat, cerca de la Bolsa. Cada país da lo suyo. Chile es famoso por sus negociantes, sus marineros y sus jugadores. (...) El aspecto tétrico de Valparaíso, que para mí se condensaba en los acordes de la ópera Guaraní, había desaparecido. Estaba en el otro lado de la ciudad, en la parte de los negocios, de las tiendas de lujo y de las tabernas de marinos (Edwards Bello 267).

Junto a los distingos del hábitat interpretado en términos de plan y cerros (y también cerro y cerros, pues no es lo mismo el Cerro Alegre que otros como el Cordillera) representado por Darío, Edwards incorpora otro espacio urbano: el Almendral (no en vano la novela se tituló también En el viejo Almendral):

Cuando los habitantes de Valparaíso quisieron parecer modernistas pusieron a sus casas techos de calamina. No solamente clavaron calamina en los techos, sino en las paredes, y las casas tomaron aspectos de latas de sardinas. La nuestra, que conservó las tejas morunas, era tenida por fea. Estaba situada en el Almendral, en la parte donde antes estuvieron los "cuartos del diablo", y los corrales de esclavos. En la época de nuestra historia, el barrio se había cultivado y era romántico (Edwards Bello 40). 
El entonces/allá que da configuración al ejercicio de la memoria se materializa en el aquí/ahora de la praxis social a través de la conservación de las tejas morunas de la casa paterna en el barrio del Almendral, que da cuenta que la familia del narrador no vive al ritmo que marca el progresismo de los migrantes europeos del barrio del Puerto, lo cual si por una parte conflictúa al protagonista, por otra incorpora con su intersección una crítica al prometeismo oligárquico monolítico, configurando un espacio representacional de la ciudad, signado por el imaginario de la complejidad, lo múltiple y lo fragmentario.

\section{EL Mitema ANARQUiSTA}

Si en la acumulación y superposición de mitemas ya se percibe tenuemente una búsqueda que avanza hacia una filantropía que combata las opresiones políticas, religiosas y sociales, esta será desplegada sin ambages por la actividad anarquista en Valparaíso. La procedencia anarquista se puede apreciar en diversas manifestaciones literarias y culturales porteñas, como la poesía de Víctor Domingo Silva y de Zoilo Escobar, en la Universidad Popular de Valparaíso (creación de ambos), en la poesía de Carlos Pezoa Véliz, los textos y las actividades vanguardistas de Zsigmond Remenyik y Julio Walton, y posteriormente, en José Santos González Vera y Manuel Rojas, entre otros.

En efecto, hacia principios del siglo xx comienza a tener representación literaria otra versión del imaginario prometeico que es asumida principalmente por sectores de la población flotante ${ }^{18}$ de bajos ingresos proveniente del interior del país y que a partir de la actividad anarquista en Valparaíso ${ }^{19}$ alcanzará una específica puesta en discurso a través de algunos poetas, intelectuales y escritores que textualizarán las experiencias del proletariado migrante, acogiendo la propuesta ácrata que se revela como el negativo del filantropismo prometeico.

18 La expresión, referida al caso del puerto de Valparaíso, la utiliza no sin ironía, Benjamín Subercaseaux en Chile o una loca geografía.

19 Para mayor información sobre el tema puede consultarse el texto de Andrés Brignardello Valparaíso anarquista. Notas para una historia social de la ciudad. 
La perspectiva anarquizante de la modernización no supone un desmantelamiento total de la fe en la técnica y el progreso, de hecho el migrante interno cree en ellos, sin embargo sostiene que esta modernización debiera estar redirigida, de allí que en estos discursos se la represente matizada de contradicciones, como en los versos del poema "Trágame" de Víctor Domingo Silva que se autodesigna "antes que poeta, revolucionario", y en que el hablante, viajero del tren que lo trae desde el interior, exclama ante el "puerto augusto y abominable":
(...) harto de sus miserias, desengañado de sus mirajes, bajo la noche i entre el tumulto del tren que avanza lanzado a escape echo mis ojos sobre su espectro con el doliente valor de un mártir i cierro el puño para decirle:
- Trágame! Trágame!...

El mismo puerto, con sus faenas y su tumulto igualitario de hombres y destinos hará exclamar a Zoilo Escobar, en un fragmento de su extenso y nunca publicado único libro Lenguas de fósforo:

Y el estremecimiento de un cristalino diáfano que crea un nuevo mundo.... y un nuevo hombre hijo de la revolución.... que aparece por todas partes ¡como un robot de acero! caminando en pureza y en línea siempre recta a la organización de la abundancia, de la cultura, y de la seguridad de la vida.

José Santos González Vera, en el relato "Una mujer", incluido en Vidas minimas, ofrece una visión de Valparaíso desde la mirada de un joven muchacho capitalino y anarquista que se queda sin trabajo y decide viajar, con el subterfugio de ir a buscar trabajo en el Puerto, en búsqueda de una mujer que conoció hace algún tiempo en reuniones políticas. La primera image de Valparaíso en este texto está fuertemente marcada por la discontinuidad: 
Íbamos por calles estrechas cuyos edificios parecían juntarse en la altura. Empezamos a trepar por una callejuela empinada que torcía a derecha e izquierda. Las casas estaban construidas en todas las formas concebibles. Algunas eran de latón; otras, de madera; éstas, de barro; aquéllas, de ladrillos, y muchas habían sido hechas con una mezcla de todo.

(...) Figurábame que los edificios habían caído de otro planeta. Las casas apretábanse desalineadamente. Unas avanzaban hacia la calle; otras se escondían; éstas descansaban en muros vecinos; aquéllas se erguían, se inclinaban, y varias ahogábanse con la presión de los edificios laterales (González Vera 83).

Esta discontinuidad podemos identificarla como un elemento esencial del "conocimiento local" que se ha ido sedimentando en Valparaíso tras todo su proceso de modernización. La expresión "los edificios habían caído de otro planeta" se nos presenta como la interpretación porteña de la aseveración kuscheana de que "no hay más universalidad que el estar caído en el suelo", expresando por esto que la cultura no puede dejar de entenderse sin la consideración fundamental del suelo que la cobija. La ciudad descrita por González Vera es la "porteñización" de la cultura y la ciudad burguesa; una cultura y ciudad que se encuentran asfixiadas por el desarrollo del "conocimiento local" de Valparaíso que interpreta geoculturalmente la propuesta universalizante de ciudad y cultura.

Este desarrollo del "conocimiento local" porteño se nos presenta por medio de los recorridos del migrante capitalino, que nos muestra espacios hasta entonces no re-presentados por los discursos anteriores. Un ejemplo significativo de ello es el Cerro Cordillera, donde el protagonista vivirá en una casa cuyo "aspecto era despersonalizado, anónimo" (González Vera 83), que contrasta casi como el negativo fotográfico del Cerro Alegre antes representado por Darío y Edwards Bello. En el Valparaíso que devela el recorrido del anarquista, el cosmopolitismo ya no es el de los comerciantes y empresarios de Edwards Bello, ni el de los banqueros de sombrero de paño y guantes de Darío. González Vera recoge -como también lo había hecho Silva en Hacia Allá- más que una existencia cosmopolita, una muchedumbre confusa que deambula merodeada por la cesantía:

Deseoso de curiosear, me fui al puerto, atravesé calles brillantes, estrechas, y luego estuve en el muelle. Encontré gente de todos los países. Unos marineros alemanes fumaban pipas. Obreros 
cesantes, acodados en las barandillas del muelle, seguían con mirada indiferente el ir o venir de los transeúntes. El mar era una monstruosa masa de elástico. Estuve largos minutos como disuelto ante la arremetida cansadora y monótona de las olas. Después anduve sin objeto (González Vera 84).

La fe ciega en el progreso que traerían las industrias, expuesta por de la Barra en "Canto a la fraternidad en la industria", se ve sometida a un juicio crítico por esta nueva realidad plasmada en el discurso migrante del relato de González Vera:

En la primera semana, Joaquín me llevó a ciertas fábricas; pero en todas me rechazaron. Las industrias languidecían. Las máquinas estaban dominadas por un sueño sin variante. Los patrones tenían el gesto afeado.

Las calles congestionábanse de obreros con las piernas flojas y los brazos en abandono. Mujeres pobrísimas vagaban aleladas. Desde el fondo de las tiendas, los comerciantes vigilaban con nerviosa preocupación el movimiento del hambre hecho hombres y mujeres (González Vera 95).

La ciudad fracturada en plan y cerros revelada por Darío y luego más agudamente por Edwards Bello, ahora acoge un tránsito sostenido entre el plan y los cerros por medio de un capitalismo "fuera de lugar", es decir, por medio de una adaptación local de la propuesta ideológica burguesa. Irónicamente, el anarquista de González Vera se incorpora al mercadillo informal del consumo local:

Con la idea de un hallazgo, me detuve extrañado ante la variedad de ventas que había en la subida de San Juan de Dios. Cubrían la acera desde el plan hasta el comienzo de la falda del cerro. Vendían carne, limones, vasijas de greda y chucherías mil, además de los frutos de la estación. Recordé que en mi maleta tenía ciertos libros perfectamente vendibles. La casualidad me condujo a una tienda en que realizaban, a veinte centavos el tomo, las obras de Rubén Darío y Joaquín Edwards Bello. Adquirí las que más pude (González Vera 97-98).

En síntesis, el movimiento de consolidación de un "conocimiento local" de Valparaíso de fines del siglo xix y comienzos del xx avanza desde una propuesta burguesa de comunidad cultural representada por la filantropía 
de Swinglehurst, que se ve desequilibrada por Rubén Darío y dislocada por Edwards Bello, para ser finalmente discontinuada y sofocada por los poetas de raigambre anarquista. Un "conocimiento local" que se erige desde la materialidad espacial de las salas, museos y edificios hacia un desarrollo particular de la "pregnancia simbólica" (Cassirer 238) que solo una interpretación consciente de su propio horizonte simbólico local puede otorgarle.

\section{VALPARAÍSO: UNA HETEROTOPÍA CRÓNICA DE LA MODERNIDAD}

En los textos revisados, las manifestaciones autónomas de las unidades de base del imaginario prometeico y su interdependencia con el espacio de representación local tienen, de manera más o menos explícita, como transfondo inevitable la relación del espacio urbano-portuario con el mar que determina su estatuto geocultural. Ahora bien, para Kusch (61), hay dos formas que puede llegar a establecer una determinada cultura para referirse al mar: referirse a él por su simple condición de fácil acceso, o bien, considerarlo en sí mismo como un ente explotable o de instrumento de soberanía.

En el caso de Valparaíso, se trata más bien de esto último. Sin embargo, para Schmitt las culturas que han mantenido con el mar una relación de dominio, en tanto elemento diferenciador de una forma de vida histórica, son aquellas que han logrado transponer un acto simbólico de la existencia humana de la tierra hacia el mar. Desde nuestro punto de vista, el acto simbólico propio de Valparaíso para con el mar se concreta paradójicamente en "un tierra adentro" que irá separando cada vez más el puerto de la ciudad que le vuelve la espalda en el barrio del Almendral o lo contempla distanciado desde la impavidez de los cerros, planteándose así un conflicto de flujos entre migrantes venidos del interior del país y de emigrantes extranjeros y sus descendientes del que se desprende una perspectiva cultural de dominio frente al mar, influencia directa del dominio comercial inglés. Sostiene Schmitt, que durante el siglo xIx se lleva a cabo la separación definitiva entre tierra (Behemot) y mar (Leviatán): "La tierra firme pertenece ahora a una docena de Estados soberanos; el mar, a nadie, a todos y, en realidad, a uno solo: Inglaterra" (Schmitt 67), siendo este el nomos de la tierra que se desprendía de aquella contingencia histórica. 
Para Schmitt, durante el período de dominio británico sobre el mar "los ingleses, y los pueblos que han sufrido su influencia se han acostumbrado a ello" (Schmitt 68). De la automatización ejercida por este dominio marítimo es que podemos comenzar a entender la particular emergencia entre el mar y el Valparaíso prometeico. Swinglehurst expresa sin reservas este sentimiento de dominio, en el poema titulado "The imperial poet", utilizando la misma metáfora bíblica de dominio marítimo retomada luego por Schmitt:

Leviatán -como él sacude el mar,

$\mathrm{Y}$ aguas hirviendo en su propio rocío;

Él es los océanos británicos libres,

Y el día que amanece del Imperio (Swinglehurst 223) ${ }^{20}$.

Pero, las similitudes con Schmitt no terminan allí. En la hoja volante anexada al ejemplar de Valparaíso songs, corregido de su puño y letra, en la que comenta su poema "El poeta imperial", es enfático en aclarar: "Hay muchas naciones, pero un solo Imperio para nosotros" ${ }^{21}$. La intención del volante es responder a la pregunta ¿quién es el Poeta Imperial?, que para Swinglehurst: "(...) es la voz de la grandeza de este país, y, sin aquella grandeza él es silencioso. (...) Él es uno en la grandeza, la anchura, la longitud, y la profundidad, con el Imperio británico, y con los océanos cuyos hijos indomables navegan"22.

Es el afluente que llega desde el ámbito europeo el que lleva a Valparaíso a un trato con el mar que redundará en la dimensión cosmopolita, modernizante y filantrópica. Los restantes flujos del imaginario prometeico entrarán en conflicto con él, en tanto para ellos el mar corresponde a un objeto de contemplación, cuya imagen más representativa podría ser la del niño de la novela de Edwards Bello que contempla el mar desde el cerro y ve un cráter abisal. Visión que instala un Valparaíso de tierra adentro, que se apropia a su modo del espacio urbano-portuario, empleando las estrategias

20 Leviathan -like he shakes the sea, / And boils in his own spray; / He is the British oceans free, / And Empire's dawning day.

21 There are many nations, but only one Empire for us.

$22(\ldots)$ is the voice of this country's greatness, and, without that greatness he is silent. (...) He is one in greatness, breadth, length, and depth, with the British Empire, and with the oceans her indomitable sons sail on. 
de lo múltiple y lo fragmentario y que funciona como contrapunto del proyecto totalizador sostenido por la modernidad y simbolizado por el mar y sus rutas comerciales. Sin embargo, las divisiones referenciales de la ciudad: puerto, Almendral, cerros, traslapan y adhieren a su arquitectura la "reserva de imaginación" (Foucault) que acarrean los barcos -la heterotopía por excelencia- de puerto en puerto. Así, las representaciones espaciales de Valparaíso en los autores revisados convergen en un ritmo de vida y en construcciones tormentosas como el océano: figuradas en imágenes de lo contradictorio y lo discontinuo en Silva y Zoilo Escobar, lo disparatado y cosmopolita en Edwards, lo alienado y discrepante en Darío. No importa si es Almendral, plan o cerro, todos llevan tierra adentro el ritmo feroz que la modernidad les trae vía marítima. Sin embargo, el mayor efecto en la emergencia prometeica de esta tensión entre los afluentes geoculturales que pujan desde el mar y desde la tierra, se encuentra en el nomos de la ciudad, en su división referencial en la que el puerto opera como sinécdoque de la Ciudad: "Única luz con que la humanidad / Reviste y engalana /Esa negra caverna de horror que es la ciudad" (Brandi Vera).

Si consideramos el hecho de que los imaginarios locales se fundan en la experiencia y las prácticas espaciales determinadas por el paisaje fundamental de cada territorio, los versos de Brandi Vera permiten pensar que en el caso de Valparaíso ese paisaje fundamental ${ }^{23}$, corresponde a la compleja y conflictiva relación puerto-ciudad, que -vamos a decirlo así-, se "teatraliza" en las relaciones plan-cerro, puerto-Almendral, Almendral-cerros, etcétera. En efecto, Valparaíso es primeramente "puerto de Santiago" 24 y durante largo tiempo es únicamente puerto. La existencia "urbana" gira en torno al puerto, que es el centro de la actividad. No obstante, a medida que la ciudad crece va apartándose de las faenas portuarias y relegando al puerto propiamente tal como un espacio que se interpone entre la ciudad y el mar. Las relaciones puertociudad se complejizan y van teatralizándose en distintos imaginarios que

23 Ese paisaje fundamental es el primer motor de las pregnancias simbólicas (Cassirer) que forman los imaginarios. Con respecto a esto mismo, Kusch indica que todo bábitat interpretado nunca y en ningún caso se da fuera de un horizonte simbólico local (Kusch).

24 "No era propiamente una ciudad, incluso podría dudarse de llamarla aldea" (Saez 55). 
se "racionalizan", conformando el "súper yo" colectivo local, dejando otros, marginados como reserva de revitalizaciones del paisaje cultural primigenio, desmitologizando el imaginario "racionalizado" y postulando otros diferentes.

El reconocimiento de esta fractura representada espacialmente y de las relaciones desprendidas de ella en el caso de Valparaíso permite proponer un imaginario prometeico instituyente frente a ese imaginario prometeico instituido que apreciamos en Swinglehurst. En ellos, el mito prometeico se definía en un mitema caracterizado por una filantropía que perseguía consolidar un valor esencializante de lo humano y la cultura humana; alternativo a esto, en Darío el prometeismo desplegaba el mitema de la búsqueda de autonomía y libertad discrepantes de cierto universalismo (alienación plan-cerro), colocando énfasis en lo local; en cambio Edwards Bello se presenta como una síntesis -conflictiva- del universalismo y lo local, de lo que viene por el mar y lo que se construye en la tierra.

Con el correr del tiempo, ese Valparaíso como espacio con una identidad diferente de la nacional dentro de la interrelación Latinoamérica/ modernidad, configurado a partir de la preponderancia comercial y cultural que tiene como fuerza dinamizadora las diversas migraciones y que trabó fuertes vínculos con el imaginario nacional, fue cediendo su lugar a nuevas tópicas del imaginario. Foucault ("Los espacios otros") llama "heterotopías crónicas" a esas heterotopías fugaces, en donde el tiempo es fútil, precario, como en las casas de veraneo habitadas solo por un par de semanas durante el año. Valparaíso con respecto a la modernidad se presenta como tal, una heterotopía crónica en tanto se constituyó y sostuvo como el espacio más propio de la modernización, mientras sus ventajas geográficas y naturales fueron funcionales a la metrópolis decimonónica.

Este hecho terminó por fraccionar las tensiones que configuraron el imaginario prometeico de Valparaíso, llevando a sus diversos fragmentos a replantear su relación con el mar, reconfigurándose, a lo largo del siglo xx, en nuevos imaginarios con elementos tanto residuales como emergentes. 
BIBLIOGRAFÍA

Brandi Vera, Pascual. Música de puerto. 1940. Sin referencia. Impreso.

Brignardello, ANdrés. Valparaíso anarquista. Notas para una historia social de la ciudad. Valparaíso: FONDART, 2006. Impreso.

Cassirer, Ernst. Filosofía de las formas simbólicas. México: Fondo de Cultura Económica, 1971. Impreso.

Chaitin, Gilbert. "Otredad. La literatura comparada y la diferencia". La literatura comparada: principios y métodos. María José Vega y Neus Carbonell, eds. Madrid: Gredos, 1998. 145-165. Impreso.

Darío, Rubén. Azul. Valparaíso: Imprenta y litografía Excelsior, 1888. Impreso.

Durand, Gilbert. Mitos y sociedades. Buenos Aires: Biblios, 2003. Impreso. Estrada, Baldomero. "Valparaíso y el proceso de industrialización en Chile a fines del siglo XIX". Valparaíso 1536-1986. Primeras Jornadas de Historia Urbana. Valparaíso: Instituto de Historia Universidad Católica de Valparaíso, 1986. Impreso.

Edwards Bello, Joaquín. Valparaíso. Santiago: Universitaria, 2004 [1963]. Impreso.

Foucault, Michel. "Los espacios otros". Disponible en: <http:// caosmosis.acracia.net/?p=1380>. Impreso.

Nietasche, la genealogía de la historia. Valencia: Pre-textos, 2004. Impreso.

García Gual, Carlos. Prometeo: Mito y Literatura. Madrid: Fondo de Cultura Económica, 2007. Impreso.

Geertz, Clifford. Conocimiento local. Ensayo sobre la interpretación de las culturas. Barcelona: Paidós, 1994. Impreso.

González Vera, José Santos. Vidas mínimas. Santiago: Nascimento, 1973 [1921]. Impreso.

Kusch, Rodolfo. Geocultura del hombre americano. Buenos Aires: Fernando García Cambeiro, 1976. Impreso.

Larrahona, Alfonso. Historia de la poesía en Valparaíso siglos XIX y XX. Valparaíso: Correo de la poesía, 1999. Impreso.

Lefebvre, Henri. The production of space. Londres: Blackwell, 1991. Impreso. 
Mellino, Miguel. La crítica poscolonial. Descolonización, capitalismo y cosmopolitismo en los estudios poscoloniales. Buenos Aires: Paidós, 2008. Impreso.

Moll, Nora. "Imágenes del 'Otro'. La literatura y los estudios interculturales". Introducción a la literatura comparada. Armando Gnisci, ed. Barcelona: Crítica, 2002. Impreso.

Neruda, Pablo. "Despedida a Zoilo Escobar". Obras completas. Tomo IV: Nerudiana dispersa I, 1915-1964. Barcelona: Galaxia Gutenberg, 2001[1963]. Impreso.

Nómez, Naín. Antología crítica de la poesía chilena. Tomo I. Santiago: LOM, 1996. Impresa.

Oslender, Ulrich. "Espacio, lugar y movimientos sociales: hacia una 'espacialidad de resistencia'". Revista Electrónica de Geografía y Ciencias Sociales, VI.115. Disponible en <http://www.ub.es/geocrit/sn/sn115.htm>. Web.

Pratt, Mary Louise. Ojos imperiales. Literatura de viaje y transculturación. Buenos Aires: Universidad Nacional de Quilmes, 1997. Impreso.

Rama, Ángel. Rubén Darío y el modernismo. Caracas: Alfadil, 1970. Impreso. Las máscaras democráticas del modernismo. Montevideo: Fundación Ángel Rama, 1985. Impreso.

Reyes, Salvador. "Valparaíso". Revista Letras 17 (1930). Disponible en < http://www.memoriachilena.cl/archivos2/pdfs/MC0014652.pdf>. Web.

Rubio, Graciela. Testimonios para una memoria social de Valparaíso 1870-1917. Valparaíso: Puntángeles, 2007. Impreso.

SÁez, Leopoldo. Valparaíso. Lugares, nombres y personajes. Siglos XVI-XXI Valparaíso: Puntángeles, 2001. Impreso.

Schmitt, Karl. Tierra y mar. Madrid: Trotta, 2007. Impreso.

Silva, Víctor Domingo. Hacia allá. Poemas orijinales. Santiago: Imprenta y encuadernación Universitaria, 1905. Impreso.

Monografía histórica de Valparaíso 1536-1910. Viña del Mar: Altazor, 2004 [1910]. Impreso.

Solar, Claudio. Historia de la Literatura de Valparaíso. Valparaíso: Gran fraternidad de escritores y artistas de Valparaíso, 2001. Impreso. 
Subercaseaux, Benjamín. Chile o una loca geografía. Santiago: Universitaria, 1973. Impreso.

Swinglehurst, Henry Edward. Valparaíso songs. Londres: Butler and Tanner, 1913. Impreso. 